\title{
Supramolecular photochemistry in zeolites: From catalysts to sunscreens*
}

\author{
Michelle N. Chrétien \\ Department of Chemistry and Biochemistry, Center for Biological Applications of \\ Mass Spectrometry, Concordia University, 7141 rue Sherbrooke O., Montréal \\ H4B 1R6, Canada
}

\begin{abstract}
Zeolites are nanoporous, crystalline aluminosilicate materials comprised of a series of strictly uniform channels and cavities repeating along the tri-directional structure of the lattice. Over the last 30 years, researchers have increasingly recognized the desirable properties of these materials as hosts for photochemical reactions. This review will endeavor to draw attention to the properties of zeolite materials that make them appealing substrates for hosting guest molecules during photochemical reactions. An overview of some classical examples in zeolite host-guest photochemistry will be presented along with a brief description of a new use for zeolite materials as protective encapsulators.
\end{abstract}

Keywords: zeolites; photochemistry; supramolecular; energy and electron transfer; reactive intermediates; sunscreens.

\section{INTRODUCTION}

Zeolites are inorganic solids closely related to the soil, sand, minerals, and clays making up the earth around us, and they have been an object of research interest for over 200 years. The first commercial synthetic zeolites (A, X, and Y) were marketed by Union Carbide Corporation in 1954 as a new class of materials for use in separation and purification; the first products were used for the drying of refrigerant and natural gas. In 1962, Mobil Oil pioneered the use of synthetic zeolite X as a cracking catalyst for petroleum refining [1]. Since this time, the market for synthetic zeolites has expanded to an annual value of more than $\$ 1.7$ billion worldwide [1]. The principal commercial applications of zeolites are as adsorbants, catalysts, and ion-exchange materials. The largest market, by volume, is the use of zeolites as cation-exchangers for "water softening" in detergent formulations. The specific uses of zeolites are highly diverse and include wastewater clean-up, heavy-metal uptake from nuclear waste, deodorizing agents in pet litters, ammonia filters in kidney hemodialysis, and hydroponic substrates for the growth of plants in zeoponics [2]. It is obvious from the plethora of commercial applications that research in the area of zeolite science is wide-ranging, from their behavior as catalysts to their use as hosts in supramolecular systems. Although the field of zeolite catalysis has been extensively studied over the past four decades, the interest of photochemists in zeolites as host systems for supramolecular photochemistry is relatively recent [1,3-7]. It was not until the mid-1980s that researchers began to explore the use of zeolite materials as a constrained media for the control of photochemical and photophysical processes [8-10]. The acknowledgment that zeolites are convenient and versatile solid hosts for a huge

*Pure Appl. Chem. 79, 1-65 (2007). A collection of invited, peer-reviewed articles by the winners of the 2006 IUPAC Prize for Young Chemists. 
variety of photochemical reactions is evidenced by the number of review articles appearing in the last 10 years on the topic of zeolite-hosted supramolecular photochemistry [11-23]. It is hoped that this review will give a flavor of the diverse and interesting research ongoing in the field of zeolite host-guest photochemistry as well as new zeolite-based materials.

\section{ZEOLITE STRUCTURE}

Zeolites are comprised of $\mathrm{TO}_{4}$ tetrahedra, where $\mathrm{T}$ is silicon or aluminum and neighboring tetrahedra are connected by bridging oxygen atoms. The tetrahedra are linked by their corners to form periodic building units (PBUs), and these building blocks are arranged in a three-dimensional manner to form channels and cages or cavities of a discrete and specific size. The lower valence of aluminum results in an overall net negative framework charge, and zeolite neutrality is achieved by the presence of chargebalancing counterions, typically alkali or alkaline earth metal cations. Taking these cations into account, zeolites can be represented by the empirical formula $\mathrm{M}_{2 / n} \cdot \mathrm{Al}_{2} \mathrm{O}_{3} \cdot y \mathrm{SiO}_{2} \cdot w \mathrm{H}_{2} \mathrm{O}$, where $\mathrm{M}$ is a cation with valence $n$ and $y$ has a value anywhere from 2 to infinity. The Si/Al ratio varies from 1 to infinity depending on the particular structure, and the lower limit of $\mathrm{Si} / \mathrm{Al}=1$ is a result of the unfavorable electrostatic interactions arising from adjacent $\left[\mathrm{AlO}_{4}\right]^{5-}$ tetrahedra [24].

Two common PBUs are the sodalite and pentasil units. The sodalite cage is the building block for many different zeolites including zeolite A and faujasite zeolites $\mathrm{X}$ and $\mathrm{Y}$. The pentasil unit is the substructure of zeolites mordenite, ZSM-5, and ZSM-11, which are characterized by an internal channel structure. These structures, along with the structure of the PBUs, are given in Fig. 1 [25].

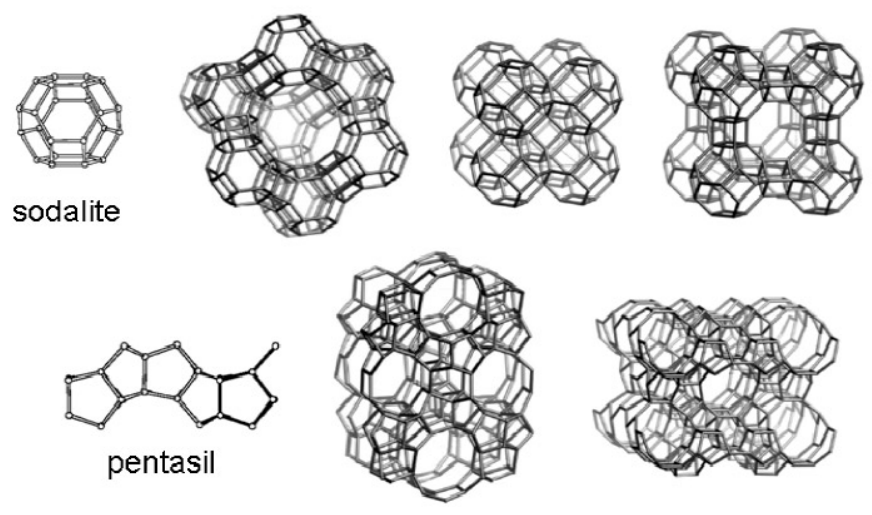

Fig. 1 Top: sodalite cage that is the building block for zeolites (from left to right) X and Y, sodalite, and zeolite A. Bottom: pentasil PBU along with the structures of zeolites ZSM-5 and ZSM-11 (compiled from ref. [25]).

The internal morphology of the faujasite family of zeolites consists of large spherical cavities or supercages that are tetrahedrally interconnected via a 12-membered ring opening, where 12 refers to the number of bridging oxygen atoms; the pore aperture is $7.4 \AA$ in the case of zeolite NaY. The supercage diameter in zeolite $\mathrm{NaY}$ is ca. $13 \AA$ and, based on the crystal structure, the supercage concentration is estimated as $6 \times 10^{-4} \mathrm{~mol} \mathrm{~g}^{-1}[16,25]$. The pore diameter and aperture size control the inclusion and intercavity diffusion of guest molecules.

Zeolite structures composed of pentasil units also have an open, three-dimensional internal structure. As opposed to the interconnecting cavity system of faujasites, pentasil zeolites have a network of two intersecting channels. These channels are round or elliptical in nature and may intersect in a straight or sinusoidal fashion. The pore openings for these medium-pore zeolites are 10-membered rings of $\mathrm{TO}_{4}$ tetrahedra. Two common pentasil materials, ZSM-5 and -11, have intersecting channels with diameters of ca. $5 \AA[26,27]$. The approximate volume at the intersection of the two channels in these zeolites is 
estimated to be $370 \AA^{3}$, corresponding to a free diameter of about $8.9 \AA$ [26]. A list of several common medium- and large-pore zeolites along with their pore and channel dimensions is given in ref. [26].

\section{CHARACTERISTICS OF THE ZEOLITE REACTION CAVITY}

\section{Microreactor size}

Typically, chemists are accustomed to carrying out reactions in vessels or containers that are disproportionately large in comparison to the size of the molecules involved. In zeolites, the size of the reaction vessel is similar in dimension to the size of the reactants themselves. Reactions occurring within the zeolite intracrystalline space can be imagined as occurring within a molecular-scale reaction vessel. When considering the role of the zeolite cavity in photochemical and photophysical processes, it is important to account for molecular restriction. The inclusion and behavior of guest molecules will depend on every aspect of the host structure, including the pore aperture, cavity size, and shape. The free volume and pore aperture are both controlled by the nature of the charge-balancing countercations, i.e., the presence of a larger cation reduces both the intracavity volume and aperture size. These cations are easily exchanged, providing a facile way to alter the cavity dimensions.

The influence of the cavity dimensions is exerted in molecular sieving where only molecules of the appropriate size and shape are permitted access to the zeolite interior. As an example, anthracene is encapsulated in $\mathrm{NaX}$ at a loading of $5.3 \times 10^{-4} \mathrm{~mol} \mathrm{~g}^{-1}$, while the loading of 9,10-dimethylanthracene is two orders of magnitude lower [28]. Once encapsulated, confinement in the zeolite further affects the reactivity by restricting certain reactive pathways, whose transition states or intermediates are not accommodated within the rigid pores, and favoring others (Fig. 2).

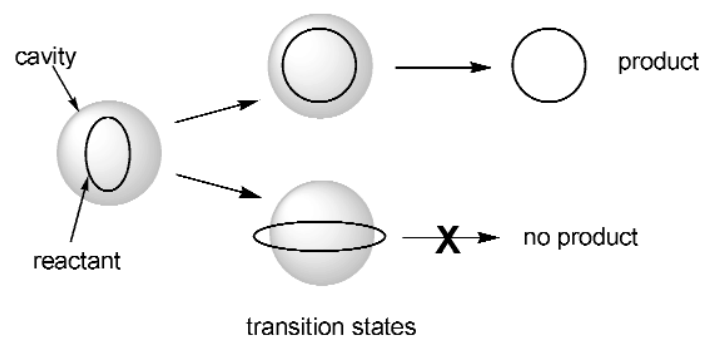

Fig. 2 Diagram illustrating the ability of the reaction cavity to disfavor certain reactive pathways in cases where the transition state is not accommodated by the non-deformable cavities.

Zeolite encapsulation can also alter guest photochemistry by imposing steric and dynamic restrictions on reactant molecules. The amount of congestion within the pore system and the presence of pores and channels of different sizes and connectivities can combine to dictate the direction and distance that an excited species or reactive intermediate can travel before relaxation or reaction occurs. In this way, reactive pathways are modulated such that products and distributions can be very different from those observed in homogeneous solution. This effect has been elegantly described by Derouane and Gabelica as "molecular traffic control" [29].

\section{Polarity and electric field}

As described above, the zeolite cavity can act as a "passive" host influencing the guest photobehavior in a steric fashion. However, the zeolite host can also influence the guest in a more "active" manner via interactions with charge-balancing cations. These cations generate large electric fields that extend into the supercage and are able to modify the environment experienced by an included guest molecule. The 
fields experienced by a guest molecule can range from 0.1 to $6.4 \mathrm{~V} \AA^{-1}$ depending on the $\mathrm{Si} / \mathrm{Al}$ ratio, the nature of the charge-balancing cation, and the distance between the cation and the guest [3]. Several general observations have been made regarding zeolite intracavity electric field: (1) the electric field is stronger at certain locations within the cavity; (2) within the same row of the periodic table, divalent cations exert a stronger field than monovalent cations; (3) the average field increases with increasing $\mathrm{Si} / \mathrm{Al}$ ratio; and (4) smaller cations within the same group produce higher fields [3]. We can predict, based on (2) and (4), that an organic guest would be polarized more readily in LiY than in CsY, and more easily in $\mathrm{CaY}$ than in NaY. It is also expected that the intrazeolite environment will favor certain reactions, such as heterolytic cleavage or electron transfer (eT), generating ions and radical ions.

The field within the zeolite cavity may be loosely thought of in terms of the polarity of a reaction medium. The two concepts are not exactly the same since the dipoles induced by a polar solvent are constantly fluctuating whereas the zeolite fields are stationary. Several attempts have been made to measure the "micropolarity" of zeolite cavities using a variety of different probes, including pyrene aldehyde [30], salicylidenes [31], and Nile red [32]. There is little specific agreement but all reports generally agree that the nature of the zeolite interior is polar. Estimates of the extent of this polarity range from that of water to aqueous acetonitrile to aqueous alcohol mixtures. Disagreements in specific values for polarity are likely due to differences in water content and sample treatment in the various experiments. The contribution of the cation to polarity is much higher in the absence of co-adsorbed water since water molecules are able to coordinate to the cations and effectively shield included probes from the cation-induced field [32].

\section{Acid and base properties}

Although the formula for $\mathrm{X}$ - and Y-type zeolites, $\mathrm{M}_{\mathrm{x} / \mathrm{n}}\left[\left(\mathrm{AlO}_{2}\right) x\left(\mathrm{SiO}_{3}\right) y\right]$, does not indicate reactive acid sites, their existence is well documented [1,3,24,33,34]. Zeolite acid and base sites can have a profound effect on guest behavior. Even a small number of acid sites can have important consequences in catalytic reactions; the unexpected protonation of olefins during catalytic oxidation is a prime example [35]. Therefore, it is imperative to take into account the acid-base properties of zeolites when considering the photobehavior of included guest molecules.

Zeolites may potentially contain both aluminol and silanol groups, inherent to the zeolite structure, as loci of Brønsted acidity. Aluminol sites are very weak, and silanol groups are only significantly acidic when adjacent to tri-coordinate $\mathrm{Al}$, i.e., a Lewis acid site; as a consequence, $\mathrm{Si}-\mathrm{OH}$ and $\mathrm{Al}-\mathrm{OH}$ groups make a limited contribution to zeolite acidity. Bridging, hydroxylic-like $\mathrm{Si}-\mathrm{O}(\mathrm{H}) \cdots \mathrm{Al}$ groups, thought to form by polarization of water molecules during activation, are typically much more important sources of Brønsted acidity in zeolites. Since it is the polarization of adsorbed water molecules by the electrostatic field of the cation that ultimately results in the formation of hydroxylic acid groups during heating, the number of acid sites generated increases linearly with the polarizing power of the cation [3]. The number of acid sites resulting from heating $\mathrm{M}^{2+}$-exchanged zeolites is greater than for $\mathrm{M}^{+}$-exchanged zeolites with acid-generating power decreasing going down the group from magnesium to barium. In the case of zeolites where the charge-balancing countercation has been exchanged for a proton (e.g., HY), Brønsted acidity is introduced directly $[1,36]$.

A number of techniques have been used to probe intrazeolite acidity. UV-vis spectroscopy was first used to characterize zeolite acidity by Walling in 1950 [37]. This method adapted the approach developed by Hammett for determining the strengths of strong solution-phase acids and relies on the use of indicator bases that change color upon protonation. This technique has been widely applied over the last 50 years but recently, new methodologies employing fluorescence spectroscopy, for example, have emerged [33]. IR and Raman spectroscopy with pyridine and ammonium probes [38-40], as well as NMR using alkylamines, trialkylphosphines, and other probes [41-44] have also become common- 
place. One recent study employing both magic-angle spinning (MAS) NMR and color indicators estimated an average of one Brønsted acid site per two unit cells (16 supercages) in zeolite $\mathrm{NaY}$ [45].

Zeolites may also contain Lewis acid sites in the form of tri-coordinate framework aluminum sites, extra-framework aluminum (EFAL), and charge-balancing countercations. Other Lewis acid sites associated with aluminum are usually only generated when the zeolite is activated at greater than $650{ }^{\circ} \mathrm{C}$. The nature and number of Lewis acid sites in zeolites are even less well characterized than their Brønsted counterparts, but it is generally true that zeolites with a decreased $\mathrm{Si} / \mathrm{Al}$ ratio have a higher Lewis acidity.

In addition to Lewis acidity, each oxygen atom in the zeolite framework is a potential Lewis base site. Framework oxygen atoms increase their negative charge when bonded to aluminum instead of silicon and, since the negatively charged framework $\mathrm{AlO}_{4}{ }^{-}$interacts with the charge-balancing cation, the basicity of the oxygen is indirectly influenced by the nature of the cation. For a zeolite of given aluminum content, the Lewis acid-base behavior will actually be controlled by the cation. Strongly acidic cations such as $\mathrm{Li}^{+}$cause the zeolite to behave more like an acid, whereas the zeolite has more basic properties when the cation is less acidic and of lower electronegativity, for example, $\mathrm{Rb}^{+}$and $\mathrm{Cs}^{+}$.

\section{Light- and heavy-atom effects}

The light-atom effect refers to the effects of smaller, lighter cations on the photoprocesses of included guest molecules. These small cations, such as $\mathrm{Li}^{+}$, have a high charge density and electrostatic potential and, as a result, have a stronger interaction with the guest molecule. The strength of the guest-cation binding interaction is directly dependent on the charge density of the cation. The light-atom effect can have consequences for both the photophysical and photochemical behavior of guests. The spectral resolution in emission spectra of olefins, arylalkyl ketones, and aromatics included in zeolites varies with the nature of the charge-balancing countercation. Variations in the intensities of vibrational bands and spectral shifts have also been observed for some aromatic molecules [27]. A classic example of modified photophysical behavior is the spectra of pyrene included in zeolites with different countercations. The intensity of the $0-0$ transition of the $S_{0} \rightarrow S_{1}$ band was found to depend on the charge density of the cation present within the supercages. It has been hypothesized that the strong interaction between the aromatic $\pi$ system and the cation may result in a slight bending of the aromatic plane, causing a reduction in symmetry [26]. A reduction in the lifetime of excited singlet and triplet states of aromatic molecules has also been observed in the case of light-atom exchanged $\mathrm{X}$ and $\mathrm{Y}$ zeolites. It is believed that this reduced lifetime is the result of enhanced radiationless processes when the aromatic molecule interacts strongly with the cation. In ketones, the light-atom effect has been observed to cause a change in the nature of the lowest triplet state [26]. Switching of the character of the lowest triplet state is a familiar phenomenon for ketones in polar solvents.

As was the case with light atoms, heavy atoms can also affect the photochemistry and photophysics of organic molecules included in zeolites. It has been observed that for fused aromatics the emission spectrum is drastically changed upon inclusion in heavy-atom-exchanged zeolites. Naphthalene, for example, exhibits characteristic blue emission when included in $\mathrm{Li}^{+}-$and $\mathrm{Na}^{+}-\mathrm{ex}-$ changed zeolites. However, as the mass of the cation increases (going to $\mathrm{Rb}^{+}, \mathrm{Cs}^{+}$, and $\mathrm{Tl}^{+}$), the blue emission is drastically reduced and a new, longer wavelength emission band appears, corresponding to the naphthalene phosphorescence. This enhanced phosphorescence has been attributed to the heavyatom effect, a well-known perturbation whereby the presence of a heavy atom increases the spin-orbit coupling in the system [46]. Heavy-atom-exchanged zeolites are observed to cause spin-orbit-induced intersystem crossing (ISC) as efficiently as heavy-atom perturbers that are covalently attached to the chromophore. 


\section{PREPARATION OF HOST-GUEST COMPLEXES}

\section{Direct inclusion}

The incorporation of guest molecules into the zeolite interior is controlled by both the size of the zeolite cavity and the size of the entrance aperture. If the guest molecule has a kinetic diameter smaller than the pore opening, it can be directly included via either vapor phase or solution inclusion. The zeolite material is commonly pretreated by heating at $400-500{ }^{\circ} \mathrm{C}$ to remove organic structure templating agents or, in the case of hydrophilic zeolites such as $\mathrm{NaY}$, to remove adsorbed water. After activation, the zeolite sample may be evacuated and exposed to the guest in the form of a gas or vapor. Alternatively, the dry zeolite can be placed in contact with a solution of the guest molecule in an appropriate solvent. In order to favor migration of the guest molecule into the polar cavities of $\mathrm{NaY}$ and to facilitate drying, a volatile, nonpolar solvent is typically used. If the guest molecule is sufficiently soluble, perfluorinated solvents are a good choice for inclusion. The average loading or occupancy $(<\mathrm{S}>=$ number of molecules/supercage $)$ of the prepared zeolite complex can be calculated by spectrometric analysis of the supernatant inclusion solution, combustion elemental analysis of the zeolite complex itself, or thermogravimetric analysis.

\section{Ship-in-a-bottle synthesis}

In the case of a guest molecule whose size cannot be accommodated by the pore aperture, other strategies must be pursued. Ship-in-a-bottle synthesis is a clever methodology for the preparation of guest molecules whose dimensions preclude direct inclusion into the zeolite nanopore [47]. As the name suggests, this is accomplished by using precursors that are small enough to freely diffuse into the zeolite interior wherein they react to form the desired molecule. Once formed, the synthesized molecules are permanently entrapped within the zeolite supercage and can neither escape nor diffuse between cavities. This strategy was initially applied to the preparation of metallic complexes $[47,48]$ but has been expanded in recent years to the synthesis of encapsulated metallophthalocyanines [49] and organic ions and molecules [50-53]. This topic has also been recently reviewed [12,34]. An ideal reaction for shipin-a-bottle synthesis is high-yielding and generates no by-products that will be permanently entrapped within the zeolite, since the only method available for purification of ship-in-a-bottle complexes is solid-liquid extraction. An acid-catalyzed reaction is often preferred in order to take advantage of the acidic nature of the zeolite cavity. The occluded complex can be characterized spectroscopically by UV-vis, IR, and MAS NMR, although low sensitivity can reduce the usefulness of NMR unless guests have been isotopically labeled. If the encapsulated guest is stable to strongly acidic conditions, the zeolite framework can be dissolved in concentrated hydrochloric or hydrofluoric acid and the guest can be recovered and analyzed directly [12]. Unfortunately, many species are unstable under these aggressive conditions.

\section{Notes on sample preparation}

Many different aspects of sample preparation and treatment can have a significant impact on the observed photobehavior of included guest molecules. These factors include incorporation temperature, drying conditions, presence of co-adsorbed water or solvent, and sample age. Due to the activation energy for diffusion within the micropores, mild heating of the inclusion slurry can have a large impact on the sample loading achieved per time as well as the homogeneity of guest distribution [12]. The drying conditions or pretreatment of the complex with air, inert gas, or vacuum can also significantly affect the subsequent behavior of the guest. In the case of air or oxygen, the effect may be as simple as the quenching of an intrazeolite excited state or reactive intermediate; for example, oxygen-induced quenching of an excited triplet state [54]. There is also the possibility of more unexpected effects, such as the "lubricating" effect observed for nitrogen, where large aromatic molecules are observed to be 
more highly mobile in nitrogen-purged samples as compared to evacuated ones. This lubricating effect was attributed to occupation of cation binding sites by nitrogen, thereby reducing the interaction between the cation and the guest molecule [55].

Many zeolites commonly used as hosts for photochemical studies of supramolecular systems are significantly hydroscopic, for example, zeolites $\mathrm{NaX}$ and $\mathrm{NaY}$, and unless special precautions are taken, water is adsorbed into the pores very quickly upon exposure to ambient moisture. This co-adsorbed water may have the effect of shielding cations, as mentioned above, but it can also play a role in intracavity crowding. The cationic dye thionin (Scheme 1) was observed to have drastically different spectroscopic properties in "wet" vs. "dry" samples of zeolite NaY since the presence of water favors the formation of the hydrated thionin $\mathrm{H}$-dimer [56]. When the water was removed, only the monomeric form of thionin was observed. The occurrence of monomeric vs. dimeric thionin within the zeolite cavities results in a drastic color change of the material from blue to pink.

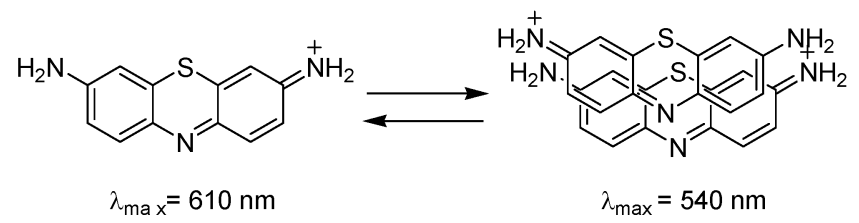

Scheme 1 Monomer and H-dimer forms of cationic thionin.

In some cases, the presence of various co-adsorbates has been observed to induce crowding to such an extent that the guest molecule is ejected from the zeolite particle interior and subsequently crystallizes on the particle surface. This has been observed for anthracene in zeolites $\mathrm{NaX}$ and $\mathrm{NaY}$ [16,57]. Guest exit from the particle interior has also been observed in similar systems by fluorescence microscopy [58,59]

Sample aging can also be an important factor in terms of guest distribution. The emission spectra recorded immediately after preparation of pyrene encapsulated in zeolite $\mathrm{Y}$ indicates the presence of predominantly the excimer (excited dimer) form, despite the fact that the calculated occupancy is well below a value indicating doubly occupied cavities [55]. Note that the molecular dimensions of pyrene are close to the size of the pore aperture. When the sample is aged over a period of one month, the emission spectrum shifts from primarily excimer to monomer in nature. Aging of the sample results in a redistribution of pyrene until an equilibrium distribution, with only singly occupied cavities, is achieved [55].

These examples are intended to emphasize the need for careful attention in the preparation of zeolite samples for photochemical studies. The effects discussed above can also help to explain the discrepancies often observed between results from different laboratories.

\section{CHARGE, ENERGY, AND ELECTRON TRANSFER IN ZEOLITES}

Charge transfer (CT) and electron transfer (eT) in zeolites have attracted considerable attention due to both the practical applications for energy storage using charge separation as well as the fundamental interest in reactions of this type. Zeolites have a demonstrated usefulness in aiding charge separation by impeding energy-wasting back electron transfer (BeT) as well as by stabilizing the photochemically generated redox species. 


\section{Charge and energy transfer}

In light of the tremendous advantages offered by the zeolite microenvironment, the large volume of work relating to $\mathrm{CT}$ and $\mathrm{eT}$ in zeolites is not surprising. The area of intrazeolite $\mathrm{CT}$ was pioneered by Kochi and Yoon in their study of arene-pyridinium CT complexes [60-64]. The formation of brightly colored CT complexes was used as a diagnostic tool to determine the shape selectivity of certain zeolite materials for guest uptake. In the case of methyl viologen $\left(\mathrm{MV}^{2+}\right)$ cation-exchanged zeolite $\mathrm{Y}$, coinclusion of anthracene results in rapid formation of the purple CT complex while contact with a solution of 9-phenylanthracene leaves the zeolite colorless, demonstrating the size restraint for CT complex formation [60]. Yoon et al. also studied the retardation of BeT in ion pairs resulting from excitation of arene-pyridinium CT complexes [62]. Photoexcitation of pyridinium-arene CT complexes in zeolite Y results in the formation of both the pyridinium and arene radical ions as products of eT and the rates of BeT were typically six orders of magnitude slower than in acetonitrile solution. Several factors, including the electrostatic and ionic environment and Coulombic interactions between the positively charged species and the negative zeolite framework were implicated in the reduced BeT rate.

Calzaferri et al. have contributed significantly to the study of energy transfer in zeolites as a part of their research devoted to the construction of artificial antenna systems [65]. For example, when pyronine (Scheme 2), a green-emitting dye, is encapsulated in the channels of zeolite L crystals, it is prevented from stacking by the molecular restriction in the channels and instead forced into an end-to-end configuration. If each cylindrical zeolite microcrystal is capped with oxonine, a red-emitting dye, selective excitation of the pyronine results in the observation of red emission as the excitation energy migrates along the column of pyronine molecules via energy transfer until it is eventually trapped by oxonine [66-68].
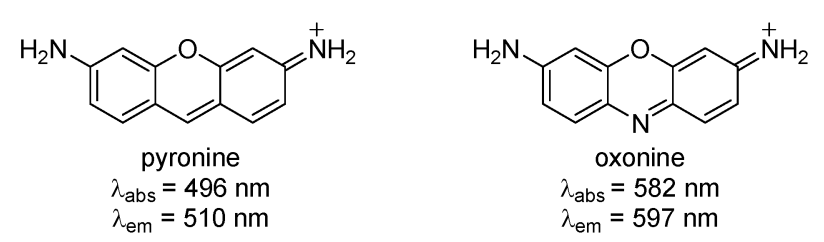

Scheme 2 Fluorescent dyes used to demonstrate energy transfer in zeolite L microcrystals.

\section{Electron transfer}

The intrazeolite photoinduced electron transfer (PeT) between tris(2,2'-bipyridine)ruthenium(II) $\left[\mathrm{Ru}^{2+}(\mathrm{bpy})_{3}\right.$ in Scheme 3] and various acceptors has been extensively studied as prototypical systems to demonstrate the possibilities for long-term charge separation. The photochemical and photophysical properties of zeolite-encapsulated $\mathrm{Ru}^{2+}(\mathrm{bpy})_{3}$ have been investigated by many researchers since its first preparation by ship-in-a-bottle synthesis in 1980 [48]. Prior to the preparation of zeolite complexes, $\mathrm{Ru}^{2+}(\mathrm{bpy})_{3}$ was observed to operate as an eT reductant in solution. Electron transfer quenching of $\left[\mathrm{Ru}^{2+}(\text { bpy })_{3}\right]^{*}$ luminescence to generate $\mathrm{Ru}^{3+}(\text { bpy })_{3}$ in the presence of trans-2-bis $(N$-methyl-4pyridyl)ethylene and $\mathrm{MV}^{2+}$ was observed in aqueous solution $[69,70]$.

Lunsford et al. noted that that the excited state of $\mathrm{Ru}^{2+}(\mathrm{bpy})_{3}$ encapsulated in zeolite $\mathrm{Y}$ is theoretically able to participate in the oxidation and reduction of water to ultimately produce $\mathrm{H}_{2}$ and $\mathrm{O}_{2}$ [48]. These processes are likely to be inefficient in solution due to highly competitive back electron and energy transfer processes. The preparation of $\mathrm{Ru}^{2+}(\text { bpy })_{3} @ \mathrm{Y}$ was aimed at providing an environment that would favor formation of the $\mathrm{Ru}^{2+}(\mathrm{bpy})_{3}$-excited $\mathrm{CT}$ state and the forward eT while reducing the efficiency of energy-wasting processes. Unfortunately, the production of $\mathrm{H}_{2}$ and $\mathrm{O}_{2}$ following irradiation was not observed in this case. 


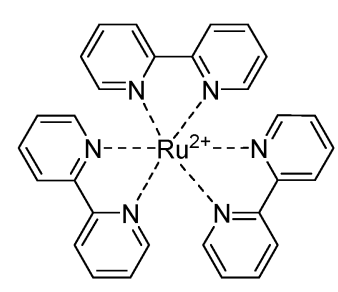

$\mathrm{Ru}^{2+}(\mathrm{bpy})_{3}$

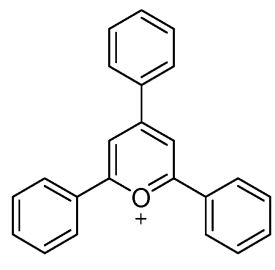

$\mathrm{TP}^{+}$

Scheme 3 Structures of tris(2,2'-bipyridine)ruthenium(II) $\left[\mathrm{Ru}^{2+}(\mathrm{bpy})_{3}\right]$ and 2,4,6-triphenylpyrylium $\left(\mathrm{TP}^{+}\right)$.

$\mathrm{Ru}^{2+}(\mathrm{bpy})_{3} @ \mathrm{Y}$ in combination with various electron acceptors (such as intrazeolitic $\mathrm{MV}^{2+}$ ) has also been explored in the context of solar energy conversion and storage. The chemistry of viologenembedded zeolites, including their eT interaction with $\mathrm{Ru}^{2+}(\mathrm{bpy})_{3}$, has recently been thoroughly reviewed [71]. In homogeneous solution, the PeT from $\mathrm{Ru}^{2+}(\mathrm{bpy})_{3}$ is followed by an efficient back reaction which can only be prevented by the presence of sacrificial electron donors [72]. The assembly of donor-acceptor pairs in heterogeneous support systems, such as zeolites, clays, and polymers, can provide the appropriate electrostatic and steric environment for the prevention of BeT, thereby favoring the generation of a long-lived charge-separated state. The study of zeolites as supramolecular scaffolds for energy storage systems (via long-lived charge separation) has been pioneered largely by Dutta et al. $[14,15,73-78]$ with significant contributions also from the groups of Kincaid [79,80] and Mallouk [81-83]. There are many examples demonstrating how intelligent use of the zeolite framework, to spatially organize the donor and acceptor components, can result in the generation of extremely long-lived charge-separated states.

In one example, the spatial organization of $\mathrm{Ru}(\mathrm{bpy})_{3}{ }^{2+}$ on the external surface of the zeolite, and the electron acceptor within the voids, resulted in an extremely long-lived charge-separated state as compared to donor-acceptor pairs in solution or in neighboring zeolite Y cages [84]. More recently, the eT between $\mathrm{Ru}(\mathrm{bpy})_{3}{ }^{2+}$, prepared in KY by ship-in-a-bottle synthesis, and a size-excluded electron acceptor was investigated [85]. This system was demonstrated to pump electrons from the zeolite framework to an externally located acceptor, under visible light irradiation. Electron transfer from the internal $\left[\mathrm{Ru}(\mathrm{bpy})_{3}{ }^{2+}\right]^{*}$ to the external viologen is mediated by migration of the charge-balancing cations, in order to maintain electroneutrality. When crown ethers were added to the solution to trap the ejected $\mathrm{K}^{+}$ cations, BeT was retarded to such an extent that the viologen cation was detected by a conventional spectrometer. This light-fuelled, single-direction electron-pumping is likely to be adapted by researchers working in the field of photocatalysis.

Zeolite materials containing $\mathrm{Ru}(\mathrm{bpy})_{3}{ }^{2+}$ and $\mathrm{TiO}_{2}$ as an electron acceptor have also been prepared in order to take advantage of the visible absorption of $\mathrm{Ru}(\mathrm{bpy})_{3}{ }^{2+}$, along with the eT-favoring properties of the zeolite, to generate $\mathrm{TiO}_{2}$-derived reactive oxygen species (ROS) using solar (visible) radiation [86]. Electron injection from $\mathrm{Ru}(\mathrm{bpy})_{3}{ }^{2+}$ into the conduction band of $\mathrm{TiO}_{2}$ was characterized spectroscopically, and the ability of this material to photocatalytically degrade biomolecules was evaluated [86]. Bossman et al. have also demonstrated $\mathrm{PeT}$ from $\mathrm{Ru}(\mathrm{bpy})_{3}{ }^{2+}$ to $\mathrm{TiO}_{2}$ where the encapsulated semiconductor acts as a relay to transfer electrons to a size-excluded Co(III) complex in solution [87]. Similarly, the intrazeolite $\mathrm{PeT}$ between $\mathrm{Ru}(\mathrm{bpy})_{3}{ }^{2+}$ and a co-encapsulated electron acceptor was shown to be modulated by the presence of $\mathrm{TiO}_{2}$ as an electron relay [88].

The combination of $\mathrm{TiO}_{2}$ with an electron-accepting moiety is much less documented. Triphenylpyrylium cation $\left(\mathrm{TP}^{+}\right.$in Scheme 3 ) is a well-established PeT sensitizer in solution and is a powerful electron acceptor in its triplet or singlet excited state [89]. Since $\mathrm{TP}^{+}$is a cation, there is no net charge separation associated with the eT step; as a result, formation of the free ions is enhanced and deactivation via $\mathrm{BeT}$ is reduced. $\mathrm{TP}^{+} @ \mathrm{Y}$ was prepared by ship-in-a-bottle synthesis, and $\mathrm{PeT}$ from $\mathrm{TiO}_{2}$ to $\mathrm{TP}^{+}$(hole injection) was evidenced by the observation of the triphenylpyranyl radical (TP*) upon vis- 
ible irradiation. Interestingly, the composite zeolite material comprising $\mathrm{TP}^{+}$and $\mathrm{TiO}_{2}$ was observed to be a better photocatalyst than $\mathrm{TiO}_{2}$ itself [86].

\section{ZEOLITES AS HOSTS FOR PHOTOCHEMICAL REACTIONS}

\section{Intrazeolite photooxidation reactions}

The selective oxidation of small hydrocarbons is one of the most important reactions in the production of organic chemicals, and molecular oxygen is a favorite oxidant for large-scale oxidations, largely due to economic factors. The photochemical oxidation of hydrocarbons has been pursued as a means of overcoming the inherent lack of product specificity in thermal oxidation reactions due to secondary chemistry. One of the most attractive approaches to photooxidation is via photoexcitation of hydrocarbon $\cdot \mathrm{O}_{2} \mathrm{CT}$ complexes.

A number of organic molecules form weak, contact CT complexes with molecular oxygen; the stabilization energy is approximately $-0.9 \mathrm{kcal} \mathrm{mol}^{-1}$ for oxygen in benzene, for example [90]. Unfortunately, in the case of small alkenes, these CT absorptions lie in the UV region, necessitating the use of high-energy photons which may reintroduce many of the problems of the thermal reaction. Frei et al. were the first to recognized the usefulness of zeolite materials in the context of stabilizing the hydrocarbon-oxygen complex and several examples of bathochromically shifted CT transitions have since been reported [91-94]. Interaction between the intrazeolite electrostatic field and the large dipole generated upon excitation of the hydrocarbon $\cdot \mathrm{O}_{2}$ complex to a CT state results in a strong stabilization of the excited state. For cis- or trans-butene, the absorption onset shifts from $350 \mathrm{~nm}$ to greater than 600 $\mathrm{nm}$ in zeolite $\mathrm{NaY}$ [92]. The use of longer wavelength photons to access low-energy photooxygenation pathways results in improved product selectivity. In the case of trans-butene, where the hydrocarbon $\cdot \mathrm{O}_{2}$ complex is stabilized by ca. $1.5 \mathrm{eV}$ in $\mathrm{NaY}$, the sole product observed was the 3-hydroperoxybutene. This photooxidation is suggested to occur via deprotonation of the alkene to generate an allyl radical and a hydroperoxy radical followed by cage recombination of these two radicals (Scheme 4).

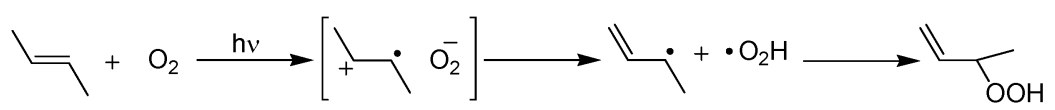

Scheme 4 Formation of the allylic hydroperoxide from photooxidation of trans-butene in zeolite NaY.

Inclusion in zeolite cavities has also been used to control selectivity in the photooxidation of organic molecules by reaction with singlet molecular oxygen $\left({ }^{1} \mathrm{O}_{2}\right)$, a highly reactive form of oxygen. ${ }^{1} \mathrm{O}_{2}$ reacts rapidly with alkenes and aromatic hydrocarbons via cycloaddition and the ene reaction (Scheme 5). The oxidation of organic sulfides also proceeds via reaction with ${ }^{1} \mathrm{O}_{2}$.

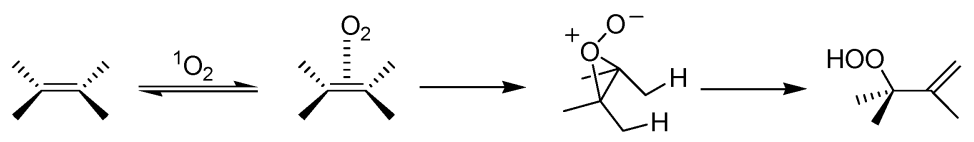

Scheme 5 Plausible mechanism for the singlet oxygen ene reaction showing the perepoxide intermediate [95].

Attempts to improve the diastereo- and enantioselectivity in these reactions have focused on control of both the substrate conformation and the geometry of singlet oxygen approach. In this context, supramolecular systems are an attractive reaction media due to their ability to organize and constrain reactants [96]. The use of zeolites is also convenient because the charge-balancing cations may be partially exchanged for the cationic sensitizers used to generate singlet oxygen, such as methylene blue, 
methylene green, and thionin. This use of zeolites to enhance ${ }^{1} \mathrm{O}_{2}$ ene regioselectivity was first introduced in 1996 [97]. Clennan et al. have since worked extensively in this area, and their work has led to the clarification of a model for the influence of the zeolite microenvironment on product regioselectivity [98].

In order to rationalize the observed regioselectivity in intrazeolite ene reactions, Clennan et al. proposed that the alkene first forms a complex with the charge-balancing cation, forcing the allylic substituent to occupy the face of the olefin approached by singlet oxygen. As the perepoxide intermediate forms, the cation shifts to electrostatically stabilize this intermediate. Steric interactions in the countercation-perepoxide "complex" control the population of each diastereomer. Electronic interactions that place more positive charge on the zeolite framework dictate the regioselectivity of the perepoxide ring opening $[95,98]$. This model was further supported by the study of a series of trisubstituted alkenes [95].

\section{Intrazeolite radical reactions}

\section{Shape selectivity}

The size and shape of zeolite cavities can also be used to control the selectivity and reactivity of photogenerated radicals. The photochemistry of unsymmetrically substituted ketones adsorbed onto or included in zeolites is a classic example of the effect of zeolite encapsulation on the fate of radical fragments [22,23,99-101]. In fluid solution, substituted ketones may undergo a Norrish I $\alpha$-cleavage to generate a primary, geminate radical pair. The subsequent steps, for an unsymmetrical ketone ACOB, are given in Scheme 6. The primary, geminate pair may undergo radical-radical recombination or decarbonylation to generate the secondary, geminate radical pair. This secondary pair can itself undergo recombination, or the two radicals can separate in the formation of a free radical pair.

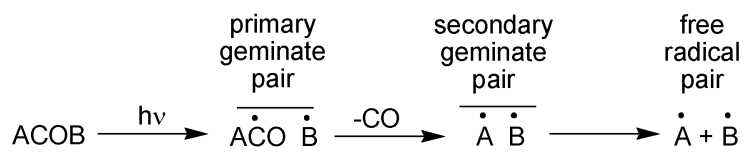

Scheme 6 Products from photolysis of unsymmetrical ketone ACOB, A and B are typically substituted benzyl moieties.

In solution, the free radicals undergo randomized radical-radical recombination reactions to give products $\mathrm{AA}, \mathrm{AB}$, and $\mathrm{BB}$ in a ratio of 1:2:1, respectively [102]. The photolysis of ACOB ketones in zeolites gives rise to stereo- and regiochemically selective radical recombinations. If, for example, the geometry of ACOB does not allow for complete encapsulation within the zeolite micropores and the smaller side of the ketone (A) resides within the channel while the bulkier side (B) is forced to remain outside, the photolysis of this complex will result in the formation of two spatially distinct radicals. Following decarbonylation, the size-excluded B radicals are free to diffuse to the surface of the particle where they will encounter and recombine exclusively with other B radicals. The internally located A radicals will diffuse within the channel system until encountering and recombining with another A radical. This molecular sieving gives rise to exclusively AA- and BB-type products [101].

This type of shape selectivity has been recently applied to demonstrate supramolecular steric effects on the dynamics of radical-radical reactivity [103]. Turro et al. have examined the fate of benzylic radicals generated via the photolysis of various substituted ketones adsorbed onto medium pore-sized, pentasil-type zeolites [104-107]. When benzylic radicals with appropriately bulky substituents were localized within the zeolite's internal channel structure, they were observed to be remarkably persistent. The persistence of radicals located on the internal surface is due to the inhibition of radical-radical reactions by the narrow diameter of the zeolite channels, termed a supramolecular steric effect. This ef- 
fect was quite dramatic in some cases, resulting in half-lives ranging from several minutes to many weeks as observed by steady-state electron paramagnetic resonance (EPR) spectroscopy [103].

The photochemistry of dibenzylketone encapsulated in the spherical cavities of zeolites $\mathrm{X}$ and $\mathrm{Y}$ provides another example of supramolecular control over radical reactions [99,101]. In this case, the free volume within the zeolite cavity was manipulated in order to control the regioselectivity of radical-radical recombination reactions. As the size of the charge-balancing cation increases, the supercage becomes more crowded, restricting diffusional and rotational motions. As steric constraints continue to increase, the formation of the least-motion product becomes dominant; in Scheme 7, the ortho isomer becomes favored over the para. This study demonstrates the remarkable control that can be exerted by merely modifying the cavity size via simple cation exchange.

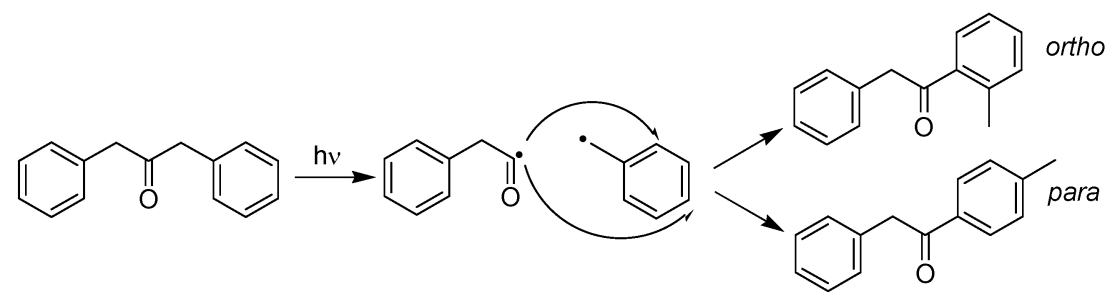

Scheme 7 Regioisomer products from the photolysis of dibenzylketone.

\section{Monitoring intrazeolite radical reactions}

It is of fundamental interest to directly probe the intrazeolite dynamics of radical species, and fluorescence is a powerful sensor in heterogeneous systems due to highly sensitive detection and the multidirectional nature of emission. Prefluorescent probes, originally reported by Blough et al., are defined as a molecular dyad consisting of a fluorophoric unit tethered to a stable nitroxyl radical (such as 2,2,6,6-tetramethyl-piperidine-1-oxyl, TEMPO) [108,109]. In its paramagnetic form, the excited singlet state of the fluorophore is efficiently quenched by the tethered nitroxide moiety corresponding to a free or "off" state. When the nitroxide oxygen couples with a carbon-centered radical ( $\mathrm{R}^{\circ}$ in Scheme 8 ) the resulting species is a diamagnetic alkoxyamine [110-113]. The quenching mode operative in the paramagnetic probe is lost, and the emission is restored, corresponding to a trapped or "on" state. There are a number of examples in the literature where this methodology has been applied to the study of radicals in other types of heterogeneous systems, e.g., polymers, micelles [114-117].

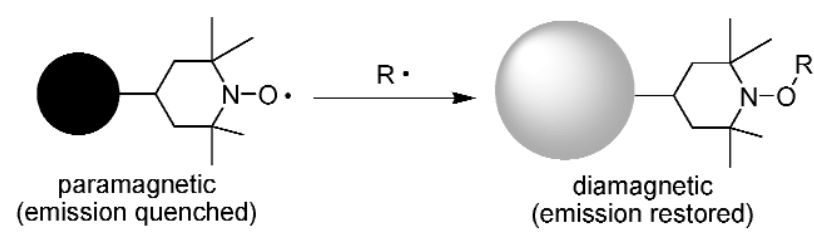

Scheme 8 Mechanism of radical detection by prefluorescent probes.

A zeolite-entrapped prefluorescent probe, based on TEMPO and the dansyl amide fluorophore [118], has been prepared using a base-catalyzed ship-in-a-bottle synthesis by first neutralizing intracavity acid sites with an organic base [119,120]. This base-catalyzed, ship-in-a-bottle synthesis is unique in the literature since typical synthetic methodologies are acid-catalyzed [19] or metal-ion templated [12].

The zeolite-bound radical probe was used to examine the formation and intercavity diffusion of carbon-centered radicals from the thermolysis of 2,2'-azobisisobutyronitrile (AIBN), a well-known 
thermal and photochemical precursor for carbon-centered radicals, commonly used as an initiator in free radical polymerization [121]. The probe was also used to study the formation and percolation of carbon-centered radicals produced by thermolysis of the size-excluded dimer, 3,3'-diphenyl-3H,3H'[3,3']bisbenzofuranyl-2,2'-dione (Scheme 9). The resulting 3-phenyl-2-coumaranone radicals (PC') are able to penetrate the zeolite pores, and the documented persistency of these radicals ensures that they will survive to migrate through the zeolite pore structure [122-126]. A fluorescence increase over time was observed as $\mathrm{PC}^{\bullet}$ radicals penetrate the zeolite pores, and encounter and couple with the embedded prefluorescent probe.

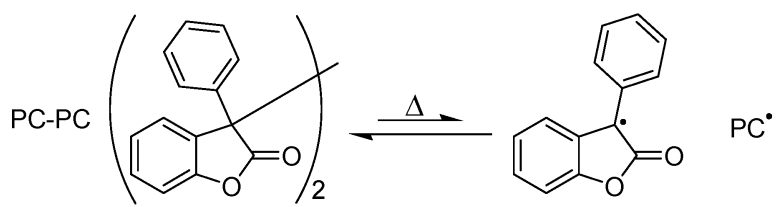

Scheme 9 Reactivity of 3,3'-diphenyl-3H,3H'-[3,3']bisbenzofuranyl-2,2'-dione.

The radical sensing ability of the prepared material should prove useful for determining mechanistic details of zeolite-catalyzed reactions thereby aiding in the intelligent design of more efficient catalytic materials. The fluorescence-based probe methodology offers greatly improved sensitivity with respect to other spectroscopic methods for radical detection, such as differential diffuse reflectance spectroscopy.

\section{Intrazeolite asymmetric photoreactions}

Stereoselective synthesis is an important facet of synthetic organic chemistry, particularly in the context of molecules with potential pharmaceutical applications. Although enormous effort has been devoted to the development of general asymmetric methodologies for ground-state reactions, less attention has been focused on asymmetric photochemical synthesis [127-129]. This area has received increased consideration in recent years, especially chiral induction in the solid or condensed state. Asymmetric photochemistry in the crystalline state requires that the achiral substrate crystallize in a chiral space group, providing the necessary environment for stereoselective reaction. Unfortunately, there are a limited number of useful compounds that will crystallize in a chiral fashion [130]. A much more general strategy developed by Scheffer et al. encourages the crystallization of achiral molecules into chiral space groups by forming a crystalline salt between a prochiral carboxylic acid-containing reactant and an optically pure, inert amine. This is called the "ionic chiral auxiliary approach" [131,132]. This methodology has lead to excellent optical yields in a wide variety of photochemical reactions, ranging from di- $\pi$-methane rearrangements to Yang photocyclization reactions [132].

Zeolites have the ability to control and constrain included guest molecules, making them a natural choice for attempts at stereocontrol in photochemical reactions. The use of zeolites as hosts for asymmetric induction takes two approaches. In the first, the achiral zeolite interior is rendered locally chiral by the inclusion of a chiral inductor such as (+)- or (-)-ephedrine [133]. The first example of asymmetric induction in the cavity of a zeolite was reported for the Norrish II conversion of cyclohexyl ketones to the corresponding butanols (Scheme 10); reported enantiomeric excesses (ee) were low to moderate. While this method has the advantage that the chiral inductor and substrate are neither covalently nor ionically bound, the ee is limited by the number of cavities in the zeolite that are occupied by both a substrate and inductor molecule. 


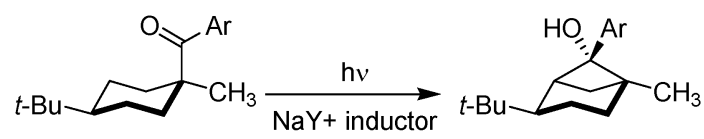

Scheme 10 Photocyclization of substituted cyclohexyl ketones to give the chiral cyclobutanol.

In order to improve selectivity, the "chiral auxiliary approach" was adapted for intrazeolite photochemical reactions. In this methodology, the chiral inductor is bonded directly to the achiral substrate so that each zeolite cavity will contain both substrate and inductor by default. This approach has worked very well in a number of cases and, together with the work on the chiral inductor method, has led to some general observations that may be useful for the intelligent design of systems for asymmetric induction $[20,134,135]$. It was observed that selectivity was dependent on the nature and number of cations and was reduced in the presence of water, leading to the conclusion that charge-balancing cations play an important role in intrazeolite asymmetric induction. The role of the cation is likely to immobilize the substrate either by cation- $\pi$ interactions or by cation-dipolar interactions with nitro or carbonyl groups. Work is still ongoing to improve both the generality and predictability of asymmetric induction in zeolites [136-138].

\section{ZEOLITES AS STABILIZING ENCAPSULATORS}

\section{Stabilization of reactive intermediates}

Zeolites are also well documented to enhance the stability of included guest species, and there are numerous examples of this in the literature. In one recent example, an electroluminescent polymer, poly( $p$-phenylenevinylene), was encapsulated in faujasite zeolite $\mathrm{Y}$, and a remarkable increase in its chemical and thermal stability was observed. Typically, the gradual oxidation of $\mathrm{C}=\mathrm{C}$ bonds in the polymer results in its degradation, reducing its utility in polymer light-emitting diodes. This oxidation process was markedly retarded within the zeolite [139].

It has also been demonstrated that a number of organic cations, having a submillisecond lifetime in solution, become indefinitely persistent when incorporated inside the rigid framework of a zeolite [50-52,140]. In one example, the encapsulated dibenzotropylium cation was observed to persist within the zeolite nanochannel for longer than 10 years. This enhanced stability allowed for the characterization of the cation triplet state as well as its eT interaction with a co-included amine [140].

Considering the overall negative framework charge for all aluminum-containing zeolites, the incorporation and stabilization of positively charged species is intuitive. By this same reasoning, zeolites as negatively charged, solid polyelectrolytes, could be expected to impede the absorption and diffusion of negative ions by electrostatic repulsion. There is a general belief that zeolites cannot incorporate and/or stabilize carbanions, and as a result there are a limited number of examples of reactive carbanions incorporated in zeolites [141,142]. In a study of the intrazeolite decarboxylation of 2-(3-benzoylphenyl)-propionic acid (ketoprofen), this species was shown to undergo spontaneous deprotonation in $\mathrm{NaY}$ to generate the carboxylate. The encapsulated species also underwent efficient photodecarboxylation to generate an extremely long-lived carbanion (Fig. 3) [143]. The photochemistry is the same as that observed in basic solution, but in the relatively anhydrous and aprotic zeolite environment, the carbanion lifetime is ca. 50 times longer than in aqueous solution $[144,145]$. It was proposed that the long lifetime is due to the absence of a proton source and a stabilizing interaction between the carbanion and the zeolite charge-balancing cations, as suggested in Fig. 3. These results prompted researchers to explore the behavior of other zeolite-stabilized carbanionic species, such as the Meisenheimer complex [142], and disabused the widely accepted notion that zeolites are ineffective hosts for reactive, negatively charged species. 


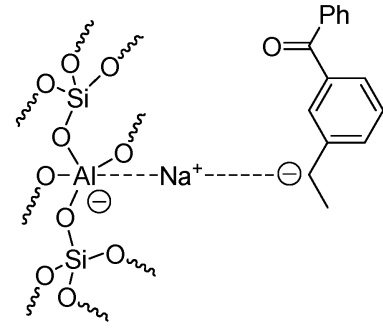

Fig. 3 Schematic representation of a possible carbanion stabilization mode in $\mathrm{NaY}$.

\section{Supramolecular sunscreens}

This last example endeavors to emphasize a relatively unexplored avenue of utility for zeolite materials, namely as protective encapsulants. Zeolites have already found some limited use in the medical sciences as MRI contrast agents and anticoagulant-releasing materials for medical implants [146,147]. Hopefully, the preliminary investigations of encapsulated sunscreens described here will provide yet another avenue of exploration for zeolite-based materials. Many of the characteristics of the zeolites discussed above make them ideal hosts for encapsulation applications; for example, the intracavity charge is useful for securing the guest molecule within the zeolite supercage. These applications exploit the zeolite cavity as a nanosegregator, as opposed to a nanoreactor, in order to organize and segregate species on a molecular level.

Our work on new sunscreen materials was partially prompted by the fact that sunscreens have become ubiquitous, appearing in products ranging from shampoo to lipstick. As public consciousness of the deleterious effects of UVB and UVA exposure (photoaging, skin cancer, etc.) has increased, the use of sunscreens amongst the general population has exploded. This increased usage has been accompanied by an increase in the reported occurrences of photoallergy and phototoxicity; it is currently estimated that ca. $20 \%$ of the population are photosensitive to one or more sunscreen active ingredients. A key example is the once-popular UVB sunscreen, $p$-aminobenzoic acid (PABA) and its derivatives, which were eventually voluntarily removed from commercial formulations due to their photoreactivity and the high incidence of reported photoallergy. PABA is now well known to sensitize the formation of singlet oxygen $[148,149]$ and has been shown to cause DNA damage both in vivo and in vitro [150].

We have shown that, although the photochemistry remains unchanged upon zeolite encapsulation, the zeolite-based sunscreen material has a significantly reduced negative impact on a model biological system [151]. Specifically, PABA-induced damage to an oxidoreductase enzyme (measured as the reduction in enzymatic activity) was reduced from 90 to ca. $20 \%$ when PABA was encapsulated in zeolite Y [151]. Similar results have been obtained for oxybenzone [152], one of the first compounds incorporated in sunscreen formulations to offer enhanced UVA protection and second only to PABA in the number of reported cases of photoallergy [153-156].

Physical or insoluble sunscreens, intended to protect the skin by scattering incident radiation in a particle-size-dependent manner, have rapidly increased in popularity over the last decade due to their effectiveness at blocking UVA radiation and to their purported safety. The most popular inorganic sunscreen is $\mathrm{TiO}_{2}$, followed by zinc oxide. These materials are increasingly used in combination with organic filters in high sun protection factor (SPF), UVB/UVA sunscreen products. In light of its known photocatalytic properties, it is somewhat surprising that $\mathrm{TiO}_{2}$ is considered a safe and effective sunscreen ingredient [157]. It has been demonstrated that the irradiation of organic sunscreens in the presence of $\mathrm{TiO}_{2}$ results in their mineralization [117]. This suggests that a commercial sunscreen product containing $\mathrm{TiO}_{2}$ would rapidly lose its efficacy upon exposure to sunlight! Preliminary experiments suggest that encapsulation of the organic filter in zeolites would preserve the stability of the organic sunscreen and protect it from $\mathrm{TiO}_{2}$-induced degradation [152]. Based on these results, it has been sug- 
gested that sunscreens could be encapsulated within the cavities of zeolite materials, giving a supramolecular sunscreen that would retain the beneficial characteristics of the parent sunscreen but prevent interaction between the skin and the sunscreen itself.

\section{CONCLUDING REMARKS}

Zeolite materials are remarkably versatile hosts for controlling photophysical processes and photochemical reaction pathways. In addition to being available in a variety of morphologies, the specific properties of a zeolite host can be finely tuned by cation modification. The examples given in this review are intended to emphasize the efficacy of zeolite encapsulation for modification of guest photobehavior. The unique properties of the zeolite cavity in terms of site isolation, compartmentalization, electrostatics, and acidity/basicity can result in photochemistry and photophysics that are very different from what is observed in the fluid phase. It is hoped that by providing an introduction to zeolite materials themselves alongside examples of their use as supramolecular hosts that the reader will gain a true insight into the multifaceted nature of this area of research. Zeolites can be used as a reaction medium to gain valuable information on the excited-state behavior of a guest molecule, as a constraining host to direct the path of photochemical reactions, and as a scaffold for the preparation of new materials with valuable and tunable properties.

The specific examples presented here really only skim the surface of the fascinating research ongoing in this field. Zeolite materials have come a long way from their traditional uses as catalysts, adsorbants, and water softeners to their use in a plethora of supramolecular photochemical systems. The field continues to expand with new zeolite applications in the medical and biological sciences as well as the use of zeolites for optical and electronics applications such as lasers, quantum dots, and second harmonic generation [16].

\section{ACKNOWLEDGMENTS}

The author is deeply grateful to Prof. J. C. (Tito) Scaiano for infinite support and guidance. Thanks also to Prof. Gonzalo Cosa for helpful discussions during the preparation this manuscript and to Prof. Hermenegildo García for his tutelage. The University of Ottawa, the Ontario Graduate Scholarship program, and the Natural Sciences and Engineering Research Council of Canada (NSERC) are acknowledged for financial support.

\section{REFERENCES}

1. H. van Bekkum, E. M. Flanigen, P. A. Jacobs, J. C. Jansen. Introduction to Zeolite Science and Practice, Elsevier Science, Amsterdam (2001).

2. F. A. Mumpton. Proc. Natl. Acad. Sci. USA 96, 3463 (1999).

3. S. M. Auerbach, K. A. Carrado, P. K. Dutta. Handbook of Zeolite Science and Technology, Marcel Dekker, New York (2003).

4. A. Corma. J. Catal. 216, 298 (2003).

5. A. Corma, H. García. Dalton Trans. 9, 1381 (2000).

6. W. F. Hoelderich, D. Heinz. Res. Chem. Intermed. 24, 337 (1998).

7. A. Corma. Chem. Rev. 97, 2373 (1997).

8. H. L. Casal, J. C. Scaiano. Can. J. Chem. 62, 628 (1984).

9. N. J. Turro, P. Wan. Tetrahedron Lett. 25, 3655 (1984).

10. S. L. Suib, A. Kostapapas. J. Am. Chem. Soc. 106, 7705 (1984).

11. A. Corma, H. García. Chem. Commun. 1443 (2004).

12. A. Corma, H. García. Eur. J. Inorg. Chem. 1143 (2004).

13. A. Corma, H. García. Top. Catal. 6, 127 (1998). 
14. P. K. Dutta. J. Inclusion Phenom. Mol. Recognit. Chem. 21, 215 (1995).

15. P. K. Dutta, Y. Kim. Curr. Opin. Solid State Mater. Sci. 7, 483 (2003).

16. S. Hashimoto. J. Photochem. Photobiol. C 4, 19 (2003).

17. V. Ramamurthy, J. Shailaja, S. Kaanumalle, R. B. Sunoj, J. Chandrasekhar. Chem. Commun. 1987 (2003).

18. V. Ramamurthy, N. J. Turro. J. Inclusion Phenom. Mol. Recognit. Chem. 21, 239 (1995).

19. J. C. Scaiano, H. García. Acc. Chem. Res. 32, 783 (1999).

20. J. Sivaguru, A. Natarajan, L. S. Kaanumalle, J. Shailaja, S. Uppili, A. Joy, V. Ramamurthy. Acc. Chem. Res. 36, 509 (2003).

21. C.-H. Tung, L.-Z. Wu, L.-P. Zhang, B. Chen. Acc. Chem. Res. 36, 39 (2003).

22. N. J. Turro. Acc. Chem. Res. 33, 637 (2000).

23. N. J. Turro. Chem. Commun. 2279 (2002).

24. D. W. Breck. Zeolite Molecular Sieves, John Wiley, New York (1974).

25. W. M. Meier, D. H. Olson. Atlas of Zeolite Structure Types, Butterworths, London (1992).

26. M. Anpo. Surface Photochemistry, John Wiley, Chichester (1996).

27. V. Ramamurthy. Photochemistry in Organized and Constrained Media, VCH, New York (1991).

28. S. Hashimoto, N. Fukazawa, H. Fukumura, H. Masuhara. Chem. Phys. Lett. 223, 493 (1994).

29. E. G. Derouane, Z. Gabelica. J. Catal. 65, 486 (1980).

30. B. H. Baretz, N. J. Turro. J. Photochem. 24, 201 (1984).

31. P. K. Dutta, W. Tubeville. J. Phys. Chem. 95, 4087 (1991).

32. S. Uppili, J. K. Thomas, E. M. Crompton, V. Ramamurthy. Langmuir 16, 265 (2000).

33. S. Corrent, P. Hahn, G. Pohlers, T. J. Connolly, J. C. Scaiano, V. Fornés, H. García. J. Phys. Chem. B 102, 5852 (1998).

34. A. Corma. Chem. Rev. 95, 559 (1995).

35. R. A. Rao, D. L. Perlstein, R. J. Robbins, P. H. Lakshminarasimhan, H.-M. Kao, C. P. Grey, V. Ramamurthy. Chem. Commun. 269 (1998).

36. A. Corma, H. García, S. Iborra, J. Primo. J. Catal. 120, 78 (1989).

37. C. Walling. J. Am. Chem. Soc. 72, 1164 (1950).

38. R. Ferwerda, J. H. van der Maas. J. Phys. Chem. 99, 14764 (1995).

39. R. D. Place, P. K. Dutta. Anal. Chem. 63, 348 (1991).

40. W. E. Farneth, R. J. Gorte. Chem. Rev. 95, 615 (1995).

41. H.-M. Kao, C. P. Grey. J. Phys. Chem. 100, 5105 (1996).

42. Q. Zhao, W.-H. Chen, S.-J. Huang, S. B. Liu. Stud. Surf. Sci. Catal. 145, 205 (2003).

43. J. F. Haw. Phys. Chem. Chem. Phys. 4, 5431 (2002).

44. L. Peng, P. J. Chupas, C. P. Grey. J. Am. Chem. Soc. 126, 12254 (2004).

45. J. K. Thomas, V. Ramamurthy. Langmuir 14, 6687 (1998).

46. P. Atkins. Concepts in Physical Chemistry, W. H. Freeman, New York (1995).

47. N. Herron. Inorg. Chem. 25, 4714 (1986).

48. W. DeWilde, G. Peeters, J. H. Lunsford. J. Phys. Chem. 84, 2306 (1980).

49. K. J. Balkus Jr. Phthalocyanines 4, 285 (1996).

50. M. L. Cano, A. Corma, V. Fornés, H. García, M. A. Miranda, C. Baerlocher, C. Lengauer. J. Am. Chem. Soc. 118, 11006 (1996).

51. M. L. Cano, F. L. Cozens, V. Fornés, H. García, J. C. Scaiano. J. Phys. Chem. 100, 18145 (1996).

52. M. L. Cano, F. L. Cozens, H. García, V. Martí, J. C. Scaiano. J. Phys. Chem. 100, 18152 (1996).

53. M. N. Chrétien, B. Shen, H. García, A. M. English, J. C. Scaiano. Photochem. Photobiol. 80, 434 (2004).

54. N. J. Turro. Modern Molecular Photochemistry, University Science Books, Sausalito (1991).

55. F. L. Cozens, M. Regimbald, H. García, J. C. Scaiano. J. Phys. Chem. 100, 18165 (1996).

56. V. Ramamurthy, D. R. Sanderson, D. F. Eaton. J. Am. Chem. Soc. 115, 10438 (1993).

57. S. Hashimoto, S. Ikuta, T. Asahi, H. Masuhara. Langmuir 14, 4284 (1998). 
58. S. Hashimoto. Res. Chem. Intermed. 30, 163 (2004).

59. S. Hashimoto, S. Yamashita. ChemPhysChem 5, 1585 (2004).

60. K. B. Yoon, J. K. Kochi. J. Am. Chem. Soc. 111, 1128 (1989).

61. K. B. Yoon, J. K. Kochi. J. Phys. Chem. 95, 3780 (1991).

62. S. Sankararaman, K. B. Yoon, T. Yabe, J. K. Kochi. J. Am. Chem. Soc. 113, 1419 (1991).

63. K. B. Yoon. Chem. Rev. 93, 321 (1993).

64. K. B. Yoon, T. J. Huh, D. R. Corbin, J. K. Kochi. J. Phys. Chem. 97, 6492 (1993).

65. G. Calzaferri. In Photofunctionalized Zeolites, M. Anpo (Ed.) p. 205, Nova Science, New York (2000).

66. K. Lutkouskaya, G. Calzaferri. J. Phys. Chem. B 110, 5633 (2006).

67. N. Gfeller, S. Megelski, G. Calzaferri. J. Phys. Chem. B 102, 2433 (1998).

68. N. Gfeller, S. Megelski, G. Calzaferri. J. Phys. Chem. B 103, 3340 (1999).

69. C. R. Bock, T. J. Meyer, D. G. Whitten. J. Am. Chem. Soc. 96, 4710 (1974).

70. H. D. Gafney, A. W. Adamson. J. Am. Chem. Soc. 94, 8238 (1972).

71. E. L. Clennan. Coord. Chem. Rev. 248, 477 (2004).

72. K. Kalyanasundaram. Coord. Chem. Rev. 46, 159 (1982).

73. P. K. Dutta, J. A. Incavo. J. Phys. Chem. 91, 4443 (1987).

74. J. A. Incavo, P. K. Dutta. J. Phys. Chem. 94, 3075 (1990).

75. P. K. Dutta, W. Turbeville. J. Phys. Chem. 96, 9410 (1992).

76. M. Sykora, J. R. Kincaid, P. K. Dutta, N. B. Castagnola. J. Phys. Chem. B 103, 309 (1999).

77. M. Vitale, N. B. Castagnola, N. J. Ortins, J. A. Brooke, A. Vaidyalingam, P. K. Dutta. J. Phys. Chem. B 103, 2408 (1999).

78. M. Borja, P. K. Dutta. Nature 362, 43 (1993).

79. M. Sykora, J. R. Kincaid. Nature 387, 162 (1997).

80. K. Maruszewski, D. P. Strommen, J. R. Kincaid. J. Am. Chem. Soc. 115, 8345 (1993).

81. Y. I. Kim, T. E. Mallouk. J. Phys. Chem. 96, 2879 (1992).

82. E. H. Yonemoto, Y. I. Kim, R. H. Schmehl, J. O. Wallin, B. A. Shoulders, B. R. Richardson, J. F. Haw, T. E. Mallouk. J. Am. Chem. Soc. 116, 10557 (1994).

83. Y. I. Kim, S. W. Keller, J. S. Krueger, E. H. Yonemoto, G. B. Saupe, T. E. Mallouk. J. Phys. Chem. B 101, 2491 (1997).

84. T. E. Mallouk, Y. I. Kim. J. Phys. Chem. 96, 2879 (1992).

85. Y. S. Park, E. J. Lee, Y. S. Chun, Y. D. Yoon, K. B. Yoon. J. Am. Chem. Soc. 124, 7123 (2002).

86. G. Cosa, M. N. Chrétien, M. S. Galletero, V. Fornés, H. García, J. C. Scaiano. J. Phys. Chem. B 106, 2460 (2002).

87. S. H. Bossman, C. Turro, C. Schnabel, M. R. Pokhrel, L. M. Payaman Jr., B. Baumeister, M. Wörner. J. Phys. Chem. B 105, 5374 (2001).

88. M. Álvaro, M. N. Chrétien, V. Fornés, M. S. Galletero, H. García, J. C. Scaiano. J. Phys. Chem. $B$ 108, 16621 (2004).

89. M. A. Miranda, H. García. Chem. Rev. 94, 1063 (1994).

90. E. A. Gooding, K. R. Serak, P. R. Ogilby. J. Phys. Chem. 95, 7868 (1991).

91. F. Blatter, H. Frei. J. Am. Chem. Soc. 115, 7501 (1993).

92. F. Blatter, H. Frei. J. Am. Chem. Soc. 116, 1812 (1994).

93. H. Sun, F. Blatter, H. Frei. J. Am. Chem. Soc. 116, 7951 (1994).

94. H. Sun, F. Blatter, H. Frei. J. Am. Chem. Soc. 118, 6873 (1996).

95. E. L. Clennan. Tetrahedron 56, 9151 (2000).

96. E. L. Clennan, J. P. Sram. Tetrahedron 56, 6945 (2000).

97. X. Li, V. Ramamurthy. J. Am. Chem. Soc. 118, 10666 (1996).

98. E. L. Clennan, J. P. Sram. Tetrahedron Lett. 40, 5275 (1999).

99. N. J. Turro. Pure Appl. Chem. 58, 1219 (1986).

100. N. J. Turro, C.-C. Cheng, L. Abrams, D. R. Corbin. J. Am. Chem. Soc. 109, 2449 (1987). 
101. N. J. Turro, Z. Zhang. Tetrahedron Lett. 28, 5637 (1987).

102. V. Ramamurthy, X.-G. Lei, N. J. Turro, T. J. Lewis, J. R. Scheffer. Tetrahedron Lett. 32, 7675 (1991).

103. T. Hirano, W. Li, L. Abrams, P. J. Krusic, M. F. Ottaviani, N. J. Turro. J. Org. Chem. 65, 1319 (2000).

104. N. J. Turro, X. Lei, S. Niu, Z. Liu, S. Jockusch, M. F. Ottaviani. Org. Lett. 2, 3991 (2000).

105. N. J. Turro, X. Lei, S. Jockusch, W. Li, Z. Liu, L. Abrams, M. F. Ottaviani. J. Org. Chem 67, 2606 (2002).

106. N. J. Turro, S. Jockusch, X. Lei. J. Org. Chem. 67, 5779 (2002).

107. N. J. Turro, X. Lei, W. Li, Z. Liu, A. McDermott, M. F. Ottaviani, L. Abrams. J. Am. Chem. Soc. 122, 11649 (2000).

108. N. V. Blough, D. J. Simpson. J. Am. Chem. Soc. 110, 1915 (1988).

109. S. A. Green, D. J. Simpson, G. Zhou, P. S. Ho, N. V. Blough. J. Am. Chem. Soc. 112, 7337 (1990).

110. V. W. Bowry, K. U. Ingold. J. Am. Chem. Soc. 114, 4992 (1992).

111. J. Chateauneuf, J. Lusztyk, K. U. Ingold. J. Org. Chem. 53, 1629 (1998).

112. A. L. Beckwith, A. L. Bowry, K. U. Ingold. J. Am. Chem. Soc. 114, 4983 (1992).

113. W. G. Skene, J. C. Scaiano, N. A. Listigovers, P. M. Kazmaier, M. K. Georges. Macromolecules 33, 5065 (2000).

114. A. Aspee, O. Garcia, L. Maretti, R. Sastre, J. C. Scaiano. Macromolecules 36, 3550 (2002).

115. A. Aspee, L. Maretti, J. C. Scaiano. Photochem. Photobiol. Sci. 11, 1125 (2003).

116. C. Coenjarts, O. G. Ballesteros, L. Llauger, J. Palfreyman, A. L. Vinette, J. C. Scaiano. J. Am. Chem. Soc. 125, 620 (2003).

117. A. Ricci, M. N. Chrétien, L. Maretti, J. C. Scaiano. Photochem. Photobiol. Sci. 2, 487 (2003).

118. A. Ricci, M. N. Chrétien, J. C. Scaiano. Chem. Mater. 16, 2669 (2004).

119. J. C. Scaiano, M. Kaila, S. Corrent. J. Phys. Chem. B 101, 8564 (1997).

120. S. Corrent, L. J. Martínez, J. C. Scaiano, H. García, V. Fornés. J. Phys. Chem. B 103, 8097 (1999).

121. J. Fossey, D. Lefort, J. Sorba. Free Radicals in Organic Chemistry, John Wiley, New York (1995).

122. P. Karafiloglou, L. P. Catteau, A. Lablanche-Combier, H. Ofenberg. J. Chem. Soc., Perkin Trans. 21545 (1977).

123. B. B. Lohray, C. V. Kumar, P. K. Das, M. V. George. J. Am. Chem. Soc. 106, 7352 (1984).

124. J. P. Catteau, P. Karafiloglou, A. Lablanche-Combier. J. Chem. Res. 3901 (1980).

125. E. V. Bejan, E. Font-Sanchis, J. C. Scaiano. Org. Lett. 3, 4059 (2001).

126. M. Frenette, C. Aliaga, E. Font-Sanchis, J. C. Scaiano. Org. Lett. 6, 2579 (2004).

127. Y. Inoue. Chem. Rev. 92, 741 (1992).

128. S. R. L. Everitt, Y. Inoue. In Molecular and Supramolecular Photochemistry, V. Ramamurthy, K. Schanze (Eds.), pp. 71-130, Marcel Dekker, New York (1999).

129. V. Ramamurthy, A. Natarajan, L. S. Kaanumalle, S. Karthikeyan, J. Sivaguru, J. Shailaja, A. Joy. In Molecular and Supramolecular Photochemistry, Y. Inoue, V. Ramamurthy (Eds.), pp. 563-631, CRC Press, New York (2004).

130. M. Sakamoto. Chem. Eur. J. 684 (1997).

131. J. N. Gamlin, R. Jones, M. Leibovitch, B. Patrick, J. R. Scheffer, J. Trotter. Acc. Chem. Res. 29, 203 (1996).

132. J. R. Scheffer. Can. J. Chem. 79, 349 (2001).

133. M. Leibovitch, G. Olovsson, G. Sundarababu, V. Ramamurthy, J. R. Scheffer, J. Trotter. J. Am. Chem. Soc. 118, 1219 (1996).

134. L. S. Kaanumalle, J. Sivaguru, N. Arunkumar, S. Karthikeyan, V. Ramamurthy. Chem. Commun. 116 (2003).

135. S. Jayaraman, S. Uppili, A. Natarajan, A. Joy, K. C. W. Chong, M. R. Netherton, A. Zenova, J. R. Scheffer, V. Ramamurthy. Tetrahedron Lett. 41, 8231 (2000). 
136. J. Sivaguru, H. Saito, M. R. Solomon, L. S. Kaanumalle, T. Poon, S. Jockusch, W. Adam, V. Ramamurthy, Y. Inoue, N. J. Turro. Photochem. Photobiol. 82, 123 (2006).

137. J. Shailaja, L. S. Kaanumalle, K. Sivasubramanian, A. Natarajan, K. J. Ponchot, A. Pradhan, V. Ramamurthy. Org. Biomol. Chem. 4, 1561 (2006).

138. A. Joy, L. S. Kaanumalle, V. Ramamurthy. Org. Biomol. Chem. 3, 3045 (2005).

139. M. Álvaro, A. Corma, B. Ferrer, M. S. Galletero, H. García, E. Peris. Chem. Mater. 16, 2142 (2004).

140. M. L. Cano, M. N. Chrétien, H. García, J. C. Scaiano. Chem. Phys. Lett. 345, 409 (2001).

141. H. García, H. D. Roth. Chem. Rev. 102, 3947 (2002).

142. J. R. Herance, J. Marquet, J. L. Bourdelande, H. García. Chem. Phys. Lett. 395, 49 (2004).

143. M. N. Chrétien, G. Cosa, H. García, J. C. Scaiano. Chem. Commun. 2154 (2002).

144. L. L. Constanzo, G. De Guidi, G. Condorelli, A. Cambria, M. Fama. Photochem. Photobiol. 50, 359 (1989).

145. F. Boscá, M. A. Miranda, G. Carganico, D. Mauleón. Photochem. Photobiol. 60, 96 (1994).

146. S. W. Young, F. Qing, D. Rubin, K. J. Balkus Jr., J. S. Engel, J. Lang, W. C. Dow, J. D. Mutch, R. A. Miller. J. Magn. Reson. Imaging 5, 499 (1995).

147. P. S. Wheatley, A. R. Butler, M. S. Crane, S. Fox, B. Xiao, A. G. Rossi, I. L. Megson, R. E. Morris. J. Am. Chem. Soc. 128, 502 (2006).

148. A. A. Shaw, L. A. Wainschel, M. D. Shetlar. Photochem. Photobiol. 55, 647 (1992).

149. J. M. Allen, C. J. Gosset, S. K. Allen. J. Photochem. Photobiol. B 32, 33 (1996).

150. A. A. Shaw, L. A. Wainschel, M. D. Shetlar. Photochem. Photobiol. 55, 657 (1992).

151. M. N. Chrétien, L. M. Migahed, J. C. Scaiano. Photochem. Photobiol. (2006). In press.

152. M. N. Chrétien, E. Heafy, J. C. Scaiano. Unpublished results.

153. C. Szczurko, A. Dompmartin, M. Michel, A. Moreau, D. Leroy. Photodermatol. Photoimmunol. Photomed. 10, 144 (1994).

154. M. Landers, S. Law, F. J. Storrs. Am. J. Contact Dermat. 14, 33 (2003).

155. P. Collins, J. Ferguson. Br. J. Dermatol. 131, 124 (1994).

156. S. Schauder, H. Ippen. Contact Dermat. 37, 221 (1997).

157. A. Fujishima, T. N. Rao, A. Tryk. J. Photochem. Photobiol. C 1, 1 (2000). 